Commission, P.O. Box 601, Nairobi, Kenya ; 1955 ; $3 s$.$) . Part 1$ of the report gives a summarized account of the initial activities of the Council and the sequence of events leading to its formation. The details of its constitution and the Order approving its establish ment are published as appendixes. Part 2 consists of reports from the four organizations themselves, namely, the East African Agriculture and Forestry, Veterinary, Fishery, and Marine Fisheries Research Organizations, respectively. They do not replace the annual scientific reports of these bodies, which will continue to be published separately. The aim is to give a general account in non-technical language of the individual problems, policies and achievements of the different organizations, and they certainly succeed in conveying the impression of well-planned research over a vast field. The agriculture and forestry report perhaps deserves special mention, for it reviews the work of the past seven and a half years, and in spite of the inevitable difficulties of a developmental phase, much has already been accomplished. The veterinary report provides an insight into the magnitude and variety of the problems confronting the livestock industry in East Africa, and the policy here will be to concentrate on relatively few, long-term and essentially East African problems. The establishment of the whole of this Organization at the new headquarters will simplify the necessary team-work. The fishery and marine fisheries reports are mainly concerned with fundamental investigations regarding the occurrence, life-cycles and feeding habits of freshwater and sea fish, together with complementary biological and hydrographic studies of their environment. Only on the basis of such knowledge can sound, economic fishery industries be built up.

\section{Electronic Recording Machine for Financial Accounting}

Trye October issue (7, No. 9; 1955) of Research for Industry, the news bulletin of the Stanford Research Institute, Menlo Park, Calif., is devoted to a description of ERMA (Electronic Recording Machine, Accounting) which has been developed in the Institute's Computer and Control Systems Laboratories for the Bank of America. The machine credits individual accounts with deposits, debits withdrawals, remembers details of all transactions, maintains correct balances, prevents overdrawing of accounts, and sorts cheques. The electronic book keeper has five input keyboards and two magnetic drums for recording up to thirty-two thousand accounts. Each cheque is identified by 'reading' information in coded-bars printed in magnetic ink on the back of the cheque. Detailed account information is stored on magnetic tapes, and monthly account statements are prepared from this information by a high-speed printer. ERMA contains 34,000 diodes and 8,000 other valves, weighs about 25 tons, uses $80 \mathrm{~kW}$. of electricity and is cooled by an airconditioning system. The first machine is to be moved to San Jose early this year to handle accounts in that area, and the Bank of America will need about thirty-seven machines to serve its branch banks in California.

\section{New Permanent-Magnet Materials}

THREE new commercial permanent-magnet materials, which are modified forms of 'Columax' and are known respectively as 'Alcomax II S.C.', 'III S.C.' and 'IV S.D.', are now being made by member firms of the Permanent Magnet Association (301 Glossop Road, Sheffield 10). The performances of these new materials are intermediate between those of 'Alcomax' and 'Columax', although preciso specifications are not given; the development of the crystal structure is limited to certain shapes and sizes, plain solid cylinders of diameter greater than $19 \mathrm{~mm}$., with length somewhat less than the diameter, being most effective. The $B-H$ curves show considerable improvement in remanent induction, coercivity and fullness factor over those of normal 'Alcomax III'. The new materials are likely to be particularly useful to manufacturers of loud-speakers.

\section{Auxin Transport in Woody Shoots}

Althобgн the polar transport of natural auxin has now been confirmed for many herbaceous and woody species of plants, the rate at which it takes place has so far only been examined directly in the coleoptile of Avena and in the gynophore of Arachis hypogaea. F. G. Gregory and C. R. Hancock (Ann. Bot., N.S., 19, 76, 451; 1955) have now described a method for the estimation of the rate of movement and the quantity transported of the natural growth hormone in standard isolated segments of apple shoots. During controlled storage, diffusible auxin is collected, and later by dividing the standard length of stem into small sections the location of the auxin front is determined, from which the rate of transport is deduced. Temperature markedly affects both rate of transport and amount of auxin transported, a maximum occurring at $27-30^{\circ} \mathrm{C}$., followed by a rapid fall to zero. The total diffusible auxin in a given length of stem is not affected by storage temperatures below $30^{\circ} \mathrm{C}$., but falls to zero at $42^{\circ} \mathrm{C}$. The rate of transport and amount transported are proportional to the oxygen tension over the range $0-5$ per cent oxygen, and there is some evidence for destruction of auxin in tensions below 2 per cent.

\section{International Association of Agricultural Librarians and Documentalists : Quarterly Bulletin}

THE International Association of Agricultural Librarians and Documentalists was founded in 1955 to "promote "internationally and nationally, agricultural library science and documentation, as well as the professional interests of agricultural librarians and documentalists". The interests of the members cover a wide field, as the term agriculture includes forestry, agricultural engineering, veterinary sciences, food and nutrition, etc. As a start, five working committees have been set up to deal, respectively, with the publication of a news bulletin, bibliography, professional problems, exchange of material and classification. The first number of the Quarterly Bulletin has now appeared, under the editorship of Mr. D. H. Boalch (Rothamsted Experimental Station, Harpenden), with the help of some twenty correspondents from various countries. It contains lists of new periodicals and reference books, and notices of forthcoming publications and congresses. Offers and requests for exchange and information regarding current professional literature naturally also find a place in a periodical of this type. The Bulletin is free to members of the Association only, the annual subscription for institutions, libraries, etc., being 50 Swiss franes or its equivalent, and for private individuals 10 francs. Inquiries regarding subscriptions should be addressed to the treasurer, Mr. T. P. Loosjes, Twentse Bank, Wageningen, Netherlands. 